\title{
Improved Sensitization of Zinc Oxide Nanorods by Cadmium Telluride Quantum Dots through Charge Induced Hydrophilic Surface Generation
}

\author{
Karthik Laxman, ${ }^{1,2}$ Tanujjal Bora, ${ }^{1,2}$ Salim H. Al-Harthi, ${ }^{3}$ and Joydeep Dutta ${ }^{1,2}$ \\ ${ }^{1}$ Centre of Excellence in Nanotechnology, School of Engineering and Technology, Asian Institute of Technology, \\ Klong Luang, Pathumthani 12120, Thailand \\ ${ }^{2}$ Chair in Nanotechnology, Water Research Center, Sultan Qaboos University, P.O. Box 17, Al Khoudh, 123 Muscat, Oman \\ ${ }^{3}$ Physics Department, College of Science, Sultan Qaboos University, P.O. Box 17, Al Khoudh, 123 Muscat, Oman \\ Correspondence should be addressed to Joydeep Dutta; dutta@squ.edu.om
}

Received 10 September 2014; Accepted 23 November 2014; Published 10 December 2014

Academic Editor: Anukorn Phuruangrat

Copyright (C) 2014 Karthik Laxman et al. This is an open access article distributed under the Creative Commons Attribution License, which permits unrestricted use, distribution, and reproduction in any medium, provided the original work is properly cited.

\begin{abstract}
This paper reports on UV-mediated enhancement in the sensitization of semiconductor quantum dots (QDs) on zinc oxide $(\mathrm{ZnO})$ nanorods, improving the charge transfer efficiency across the QD-ZnO interface. The improvement was primarily due to the reduction in the interfacial resistance achieved via the incorporation of UV light induced surface defects on zinc oxide nanorods. The photoinduced defects were characterized by XPS, FTIR, and water contact angle measurements, which demonstrated an increase in the surface defects (oxygen vacancies) in the $\mathrm{ZnO}$ crystal, leading to an increase in the active sites available for the QD attachment. As a proof of concept, a model cadmium telluride (CdTe) QD solar cell was fabricated using the defect engineered $\mathrm{ZnO}$ photoelectrodes, which showed $\sim 10 \%$ increase in photovoltage and $\sim 66 \%$ improvement in the photocurrent compared to the defect-free photoelectrodes. The improvement in the photocurrent was mainly attributed to the enhancement in the charge transfer efficiency across the defect rich QD-ZnO interface, which was indicated by the higher quenching of the CdTe QD photoluminescence upon sensitization.
\end{abstract}

\section{Introduction}

The interfacial chemistry between two semiconductors or a metal and a semiconductor is important in determining the charge transfer across the interface that dictates the performance in areas like catalysis [1], solar cells [2], and other schemes involving charge separation processes. In a structure comprising a semiconductor QD deposited on top of a high surface area semiconducting nanostructured oxide, like in the sensitized solar cells, the current flowing across the QD-oxide junction is directly proportional to the distance between the QDs and the oxide material $[2,3]$. This is especially important in quantum dot (QD) sensitized solar cells (QDSSC), where the QDs are deposited on oxide supports with the use of linkers, which increases the distance between the two semiconductors and thus generates lower current densities as compared to linker-free or directly attached QDs [4]. On the flip side, QDs deposited without linker molecules are randomly sized which limits their use in wavelength specific applications like light emitting diodes (LEDs) and rainbow solar cells [5]. Additionally, energy band mismatches between the two semiconductors can further hinder electron hopping from the excited state of the QD to the supporting oxide [6-8].

As a supporting oxide, $\mathrm{ZnO}$ nanostructures with their wide band gap $(3.37 \mathrm{eV})$ and high electron mobility have been extensively used in sensitized solar cells $[9,10]$. In particular, the well-defined morphology and the facile formation of single crystalline $\mathrm{ZnO}$ nanorods (NRs) have attracted attention as a suitable photoelectrode (PE) [11, 12]. ZnO crystal comprises a zinc rich polar plane (0001) together with mixed terminated planes $(0110,1010$, and 1100$)$, which are relatively nonpolar in nature [13]. Modification of the surface energy of these nonpolar crystal planes by ligand functionalization 
$[14,15]$ and nanoparticle coating [16] enhances the QD loading factor and hence NR usability in solar cells [17].

In this work we have shown the modification of NR surface energy by the incorporation of defects using beyond band gap (UV-c) photoirradiation of its surface for prolonged periods [18], reducing $\mathrm{ZnO}$ crystal stoichiometry and rendering its surface hydrophilic $[19,20]$. We use the $\mathrm{ZnO}$ crystal nonstoichiometry to uniformly enhance surface energy, without any chemical modification, and employ this technique to demonstrate an improvement in the interfacial charge transfer at the QD-ZnO interface in a model quantum dot sensitized solar cell.

\section{Materials and Methods}

2.1. Materials. Analytical grade zinc acetate dihydrate $\left[\mathrm{Zn}\left(\mathrm{CH}_{3} \mathrm{COO}\right)_{2} \cdot 2 \mathrm{H}_{2} \mathrm{O}\right]$, zinc nitrate hexahydrate $\left[\mathrm{Zn}\left(\mathrm{NO}_{3}\right)_{2}\right.$. $6 \mathrm{H}_{2} \mathrm{O}$ ] from Merck, and hexamethylenetetramine $\left(\mathrm{C}_{6} \mathrm{H}_{12} \mathrm{~N}_{4}\right)$ from Aldrich were used for the synthesis of $\mathrm{ZnO}$ NRs. Chloroplatinic acid $\left(\mathrm{H}_{2} \mathrm{PtCl}_{6} \cdot \mathrm{H}_{2} \mathrm{O}\right)$, sodium sulphide $\left(\mathrm{Na}_{2} \mathrm{~S}\right)$ from Qualigens, sublimated sulphur from Panreac (PRS), potassium chloride $(\mathrm{KCl})$ from Carlo Erba, and methanol from Emsure were obtained. Fluorine doped tin oxide $\left(\mathrm{SnO}_{2}\right.$ : F) coated conducting glass substrates (FTO, $12 \Omega / \mathrm{cm}^{2}$ ) were sourced from Nippon Sheet Glass, Japan. Sodium tellurite $\left(\mathrm{Na}_{2} \mathrm{TeO}_{3}\right)$ and 3-mercaptopropionic acid $\left(\mathrm{HSCH}_{2} \mathrm{CH}_{2} \mathrm{CO}_{2} \mathrm{H}\right)$ were procured from Aldrich Chemicals; cadmium chloride $\left(\mathrm{CdCl}_{2} \cdot 5 \mathrm{H}_{2} \mathrm{O}\right)$, sodium borohydride $\left(\mathrm{NaBH}_{4}\right)$, and trisodium citrate dihydrate $\left(\mathrm{C}_{6} \mathrm{H}_{5} \mathrm{Na}_{3} \mathrm{O}_{7}\right.$. $2 \mathrm{H}_{2} \mathrm{O}$ ) were acquired from Merck. All chemicals were of analytical grade and were used without further purification processes.

2.2. $\mathrm{ZnO}$ Nanorod Synthesis. $\mathrm{ZnO}$ nanorods were grown hydrothermally on microscope glass substrates and fluorine doped tin oxide (FTO) substrates as per our previous reports $[13,21]$. The substrates were precleaned by successive sonication in soap water, ethanol, acetone, and deionised (DI) water for 15 minutes each and dried in an oven until further use. A $\mathrm{ZnO}$ seed layer was deposited on the cleaned substrates by spraying $15 \mathrm{~mL}$ of $10 \mathrm{mM}$ zinc acetate dihydrate $\left[\mathrm{Zn}\left(\mathrm{CH}_{3} \mathrm{COO}\right)_{2} \cdot 2 \mathrm{H}_{2} \mathrm{O}\right]$ solution in DI water at a rate of $1 \mathrm{~mL} / \mathrm{min}$ (from a distance of $20 \mathrm{~cm}$ ), where the cleaned substrates were preheated at $420^{\circ} \mathrm{C}$ on a hot plate. Seeded substrates were then allowed to cool naturally and were subsequently placed in a chemical bath containing equimolar $(20 \mathrm{mM})$ concentration of zinc nitrate hexahydrate $\left[\mathrm{Zn}\left(\mathrm{NO}_{3}\right)_{2} \cdot 6 \mathrm{H}_{2} \mathrm{O}\right]$ and hexamethylenetetramine $\left(\mathrm{C}_{6} \mathrm{H}_{12} \mathrm{~N}_{4}\right)$ solution in DI water at $95^{\circ} \mathrm{C}$ for 20 hours; the solution was replenished every 5 hours to obtain uniform nanorod growth [22]. The $\mathrm{ZnO}$ NR coated substrates were then removed from the chemical bath and rinsed thoroughly with DI water and some samples were annealed in air at $350^{\circ} \mathrm{C}$ for 60 minutes prior to further use.

2.3. CdTe Quantum Dot Synthesis. CdTe quantum dots were synthesized following a previous report [23] with minor modifications. In brief, $0.12 \mathrm{M}$ of cadmium chloride $\left(\mathrm{CdCl}_{2}\right)$ was dissolved in $8 \mathrm{~mL}$ of DI water and then diluted to $84 \mathrm{~mL}$ with constant stirring. To this solution $0.024 \mathrm{M}$ trisodium citrate dihydrate, $0.03 \mathrm{M} \mathrm{Na}_{2} \mathrm{TeO}_{3}$ in $8 \mathrm{~mL}$ of DI water, $0.011 \mathrm{M}$ 3-MPA, and $0.086 \mathrm{M} \mathrm{NaBH}_{4}$ were successively added with constant stirring to make the CdTe QD stock solution. This stock solution was refluxed for 20 minutes in a commercial microwave oven (in low power mode) to precipitate the CdTe QDs which were then washed several times in DI water and resuspended in DI water.

2.4. Ultraviolet (UV) Annealing of ZnO NRs in Ultrahigh Vacuum (UHV) and in Ambient Air. For UHV UV annealing, as-prepared and air-annealed $\mathrm{ZnO}$ NRs on glass substrates were subjected to high energy UV irradiation $(21 \mathrm{eV})$ under $10^{-10}$ mbar pressure for a period of 40 minutes. For ambient air UV annealing, as-prepared and air-annealed $\mathrm{ZnO}$ NRs were exposed to 12 Watts of $4.9 \mathrm{eV} \mathrm{UV-c}$ irradiation for 180 minutes, by keeping the substrates at a distance of $3 \mathrm{~cm}$ from the UV lamps (Philips TUV 6W germicidal lamps) in the ambient air.

2.5. Solar Cell Assembly and Characterization. Solar cells with an active area of $0.25 \mathrm{~cm}^{2}$ were fabricated by thermally fusing (using DuPont Surlyn 1702) ZnO-CdTe photoelectrode (PE) and platinized FTO $(0.5 \mathrm{mM}$ hexachloroplatinate $)$ counterelectrode (CE). Two holes predrilled in the CE allowed filling of polysulfide electrolyte acting as the redox agent. The PE was fabricated by immersing air-annealed and UV-annealed (in the ambient air) $\mathrm{ZnO} \mathrm{NR}$ coated FTO substrates into a concentrated CdTe QD colloidal solution $(2.06 \mathrm{~g} / \mathrm{L})$. The substrates were kept immersed at $70^{\circ} \mathrm{C}$ for 3 hours to allow adsorption of QDs on the $\mathrm{ZnO}$ NR surface, followed by drying in air at $70^{\circ} \mathrm{C}$. For UV-annealed samples, exposure to UV$c$ irradiation in the ambient air was carried out for $180 \mathrm{~min}-$ utes prior to the QD deposition. The counterelectrode (CE) was prepared by dropping $7 \mu \mathrm{L}$ of $5 \mathrm{mM}$ hexachloroplatinate hydrate $\left(\mathrm{H}_{2} \mathrm{Cl}_{6} \mathrm{Pt} \cdot \mathrm{H}_{2} \mathrm{O}\right)$ solution dissolved in isopropanol on cleaned FTO substrates. The substrate was then left to dry at room temperature, followed by annealing in air at $385^{\circ} \mathrm{C}$ for 30 minutes. Electrolyte was prepared as per previous reports [24]. In brief, $2 \mathrm{M}$ sublimated sulphur, $0.6 \mathrm{M} \mathrm{Na}_{2} \mathrm{~S}$, and $0.2 \mathrm{M}$ $\mathrm{KCl}$ were dissolved in $50 \mathrm{~mL}$ solution mixture of DI water and methanol in the ratio of $3: 7$, respectively. The assembled cell was characterized using Sciencetech 150W Small Beam Solar Simulator (SF150) under AM1.5 G illumination $\left(100 \mathrm{~mW} / \mathrm{cm}^{2}\right)$. Keithley 617 Programmable Electrometer was used as an input voltage source and a current meter, to measure the output current and record the current-voltage $(I-V)$ characteristics of the devices.

2.6. Characterization. CdTe quantum dots were characterized using JOEL JEM 2010 high resolution transmission electron microscope working at $20 \mathrm{KV}$, while the $\mathrm{ZnO}$ nanorods were characterized using field emission scanning electron microscope (SEM, IE350FSG FESEM), working at $30 \mathrm{KV}$. $\mathrm{X}$-ray diffraction measurements of $\mathrm{ZnO} \mathrm{NR}$ thin films on glass substrates were carried out by Rigakuminiflex 600 $\mathrm{XRD}$ system with a $\mathrm{Cu} \mathrm{K} \alpha \mathrm{X}$-ray source (wavelength $\sim 1.54$ 
angstrom). Water contact angle (WCA) measurements were made by dropping $5 \mu \mathrm{L}$ of water on air-annealed $\mathrm{ZnO} \mathrm{NR}$ coated glass substrates before and after exposing them to $4.9 \mathrm{eV} \mathrm{UV}-\mathrm{c}$ irradiation for varying periods of time. Between each measurement, the NR substrates were annealed at $100^{\circ} \mathrm{C}$ in air for 30 minutes. WCA was recorded with a customized contact angle instrument equipped with Dino Lite Pro AM 413T digital microscope camera [19]. WCA values were determined using ImageJ Analysis software, following a method described previously [25]. Steady state absorption and emission of the QDs were characterized by Perkin Elmer Lambda 25 and Perkin Elmer LS-55 Fluorescence Spectrometer, respectively. Photoluminescence (PL) measurements on $\mathrm{ZnO}-\mathrm{CdTe} \mathrm{PEs}$ were made by sensitizing the $\mathrm{ZnO} \mathrm{NRs}$ (with and without UV treatment) with a monolayer of CdTe QDs, followed by exciting the PEs with a wavelength of $450 \mathrm{~nm}$ and collecting the emission up to $700 \mathrm{~nm}$, based on CdTe QD PL peak at $540 \mathrm{~nm}$. Xray photoelectron spectroscopy (XPS) measurements were carried out using Omicron Nanotechnology system using a monochromatic $\mathrm{Al} \mathrm{K} \alpha$ radiation $(h v=1,486.6 \mathrm{eV})$ at $10^{-10} \mathrm{mbar}$ base pressure. The source voltage and emission current were $20 \mathrm{kV}$ and $20 \mathrm{~mA}$, respectively. Deconvolutions of the peaks were performed by Casa XPS software (Fairley, N. CASA XPS, version 2.0). Infrared spectroscopy measurements were made on Avatar 360 HATR (horizontal attenuated total reflection (HATR)) FTIR Spectrometer from Thermo Nicolet after detaching the ZnO NRs from the glass substrates. The spectrum was measured on air-annealed NRs in powder form before and after exposing them to $4.9 \mathrm{eV} \mathrm{UV}$ c irradiation for 180 minutes in ambient air.

\section{Results and Discussion}

The hydrothermally synthesized $\mathrm{ZnO}$ nanorods (NRs) which were used as the supporting oxide have a length and diameter of $\sim 3.5 \mu \mathrm{m}$ and $\sim 70 \mathrm{~nm}$, respectively, as observed from the scanning electron micrographs with a preferential orientation in the 002 axis, as observed from the XRD pattern (Figure 1). Absorption and emission spectra of aqueous cadmium telluride quantum dots (CdTe QDs) used as a model QD show peaks at $500 \mathrm{~nm}$ and $550 \mathrm{~nm}$, respectively (Figure 2(a)). From the corresponding selected area electron diffraction (SAED) pattern and HRTEM images (Figure 2(b)), it can be observed that the QDs are nearly monocrystalline in nature with a diameter of $\sim 5 \mathrm{~nm}$ (Figure $2(\mathrm{~b})$ ), which was confirmed by dynamic light scattering based particle size measurement (Supplementary Information Figure S1 in Supplementary Material available online at http://dx.doi.org/10 $.1155 / 2014 / 919163)$. The effect of UV light induced defects on the interfacial charge transfer efficiency was examined by fabricating model solar cells by depositing a monolayer of CdTe QDs on top of the $\mathrm{ZnO}$ nanorods with and without exposure to UV-c light (see experimental section) and measuring the current density across the $\mathrm{CdTe}-\mathrm{ZnO}$ interface.

The measured $I-V$ response of three individual solar cells (Supplementary Information Figure S3) shows an average increase of $66 \%$ in the short circuit current density along with a $10 \%$ increase in open circuit voltage for UV-c light exposed

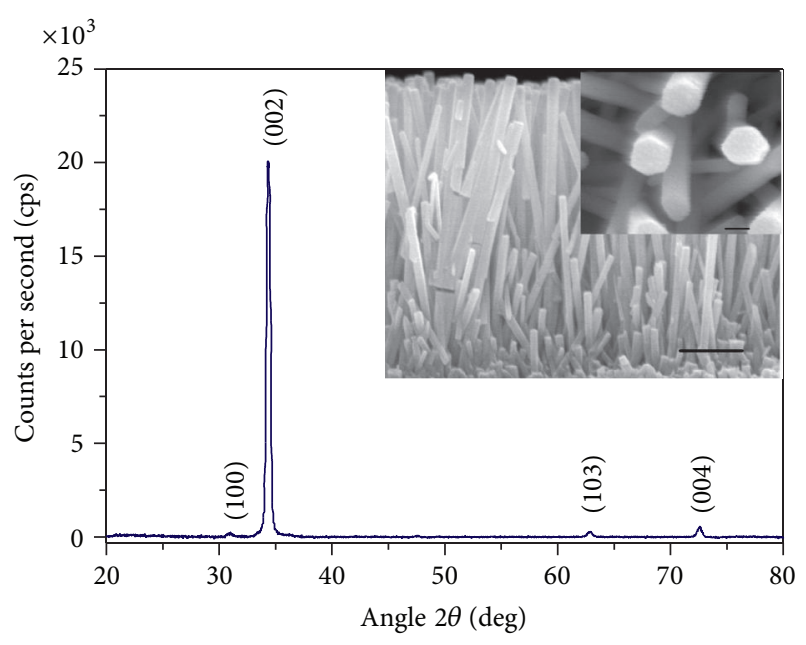

Figure 1: X-ray diffraction (XRD) peaks of hydrothermally synthesized wurtzite $\mathrm{ZnO}$ nanorods using equimolar $(20 \mathrm{mM})$ solution mixture of zinc nitrate $\left(\mathrm{Zn}\left(\mathrm{NO}_{3}\right)_{2}\right)$ and hexamethylenetetramine at $90^{\circ} \mathrm{C}$ showing preferential orientation along the 002 axis and field emission scanning electron microscopy (FESEM) images of $\mathrm{ZnO}$ nanorods (inset).

photoelectrodes (UVPEs) as compared to non-UV-exposed or air-annealed $\mathrm{ZnO}$-CdTe photoelectrodes (PPEs) (Table 1). It is to be noted that the current density can be increased by increasing the QD deposition layers (Supplementary Information Table S1) but was limited to a monolayer for better comparison of the interfacial processes. SEM images of two PEs point to increased and more uniform distribution of CdTe QDs on the ZnO NRs exposed to UV-c irradiation as compared to air-annealed $\mathrm{ZnO}$ nanorods, where moderate agglomeration and nonuniform surface coverage of the QDs could be observed (Figure 3 ).

Previous reports have suggested that $\mathrm{ZnO}$ exposure under UV light can lead to the formation of surface defects, specifically oxygen vacancies [18], which can increase surface hydrophilicity. This is advantageous for the deposition of aqueous QDs on $\mathrm{ZnO}$, as it increases the interaction of water media with the $\mathrm{ZnO}$ surface, leading to increase in the surface area available for QD deposition. We were able to confirm the change in hydrophilicity by water contact angle (WCA) measurements made on $\mathrm{ZnO}$ nanorod surfaces before and after UV-c exposure, where UV-exposed $\mathrm{ZnO}$ showed a dramatic WCA reduction from $100^{\circ}$ to $\sim 12^{\circ}$ after 180 minutes of UV-c irradiation (Figure 4(a)), indicating a substantial change in the surface energy of the nanorods [19]. The increased surface energy results from the donation of photogenerated electrons to surface adsorbed $\mathrm{O}_{2}$ and $\mathrm{H}_{2} \mathrm{O}$, leading to the creation of surface adsorbed superoxide anions $\left(\mathrm{O}_{2}{ }^{-}\right)$and hydroxyl radicals. The photogenerated holes in turn migrate to the surface providing a site for dissociative adsorption of atmospheric moisture $[18,19,26]$, which was evident in the infrared spectroscopy (FTIR) spectra, which showed a considerable increase in surface hydroxyl adsorption and a distinct broadening and bathochromic shift of the hydroxyl peaks (Figure 4(b)). The hydroxyl peaks were identified at a lower energy $\left(3400 \mathrm{~cm}^{-1}\right)$ in UV-exposed rods, which is characteristic of 


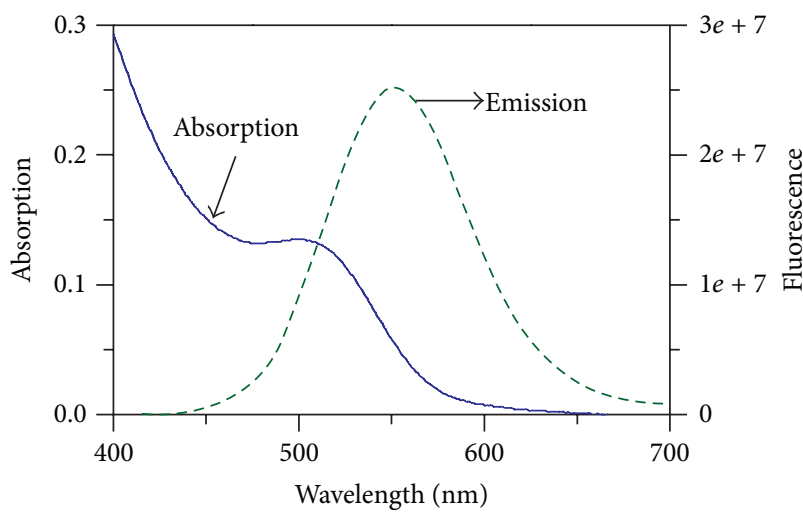

(a)

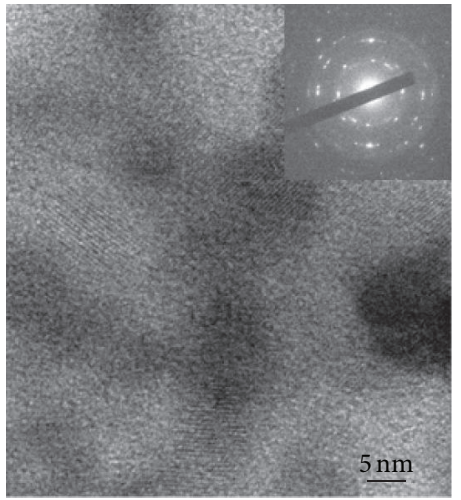

(b)

FIgURE 2: (a) Absorption and emission of cadmium telluride quantum dots (CdTe QDs) samples used for the preparation of photoelectrodes of solar cells. The emission was triggered by exciting the QDs at $445 \mathrm{~nm}$; (b) high resolution transmission electron microscope (HRTEM) of as-synthesized CdTe QDs showing single-crystalline nature of QDs (inset) small area electron diffraction (SAED) pattern of CdTe QDs.

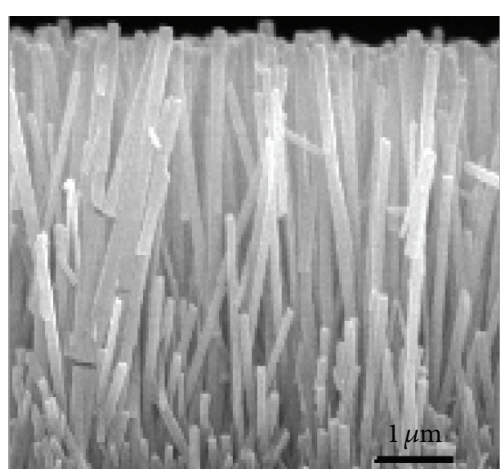

(a)

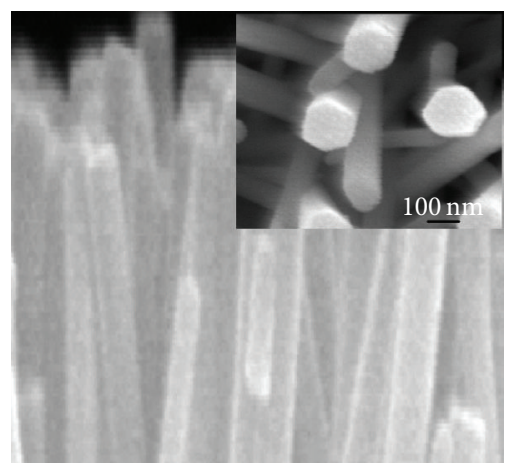

(d)

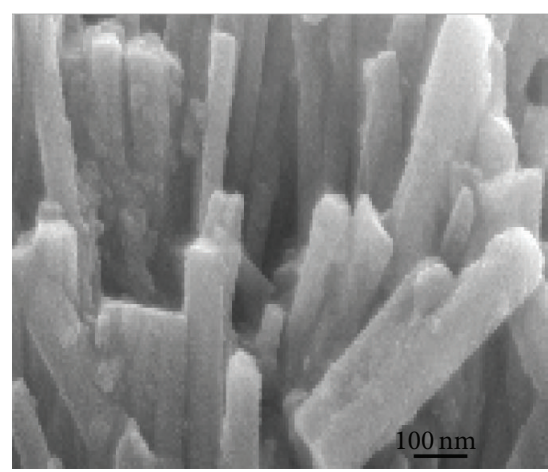

(b)

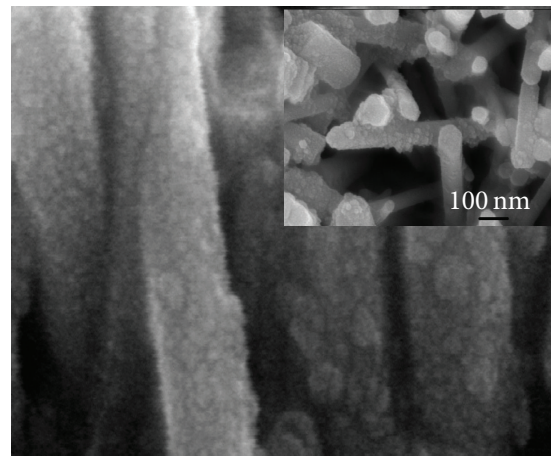

(e)

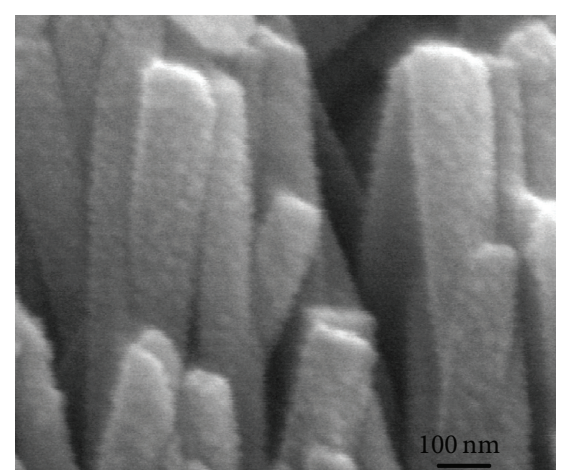

(c)

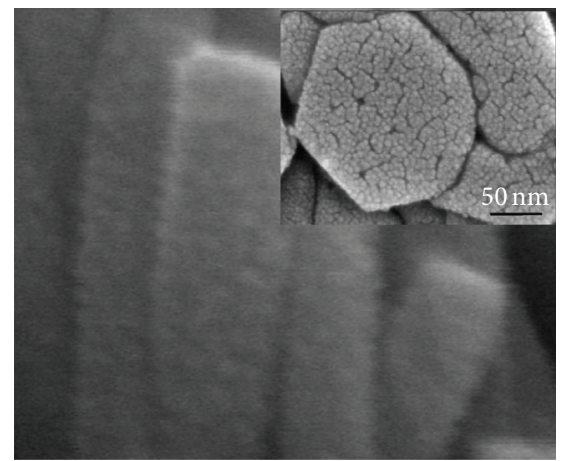

(f)

FIGURE 3: Field emission scanning electron microscope (FESEM) images of CdTe QDs decorated on ZnO NRs showing a comparison of (a) bare air-annealed ZnO NRs; (b) CdTe QD decorated air-annealed ZnO NRs, and (c) CdTe QD decorated ultraviolet (UV) light annealed ZnO NRs; (d), (e), and (f) show close-up of the (a), (b), and (c) images while the insets in (d), (e), and (f) show top view of the same samples at different areas. UV-annealed defect engineered ZnO NRs show well distributed CdTe QDs along the cross section and tips of the NRs compared to annealed $\mathrm{ZnO}$ NRs.

intermolecular strongly hydrogen bonded O-H [27]. Broadening of the $\mathrm{O}-\mathrm{H}$ peaks was also observed, which shows that the hydroxyl ions are bonded to $\mathrm{ZnO}$ surface with varying energies, where the higher energy $\mathrm{O}-\mathrm{H}$ stretch peaks $\left(3790 \mathrm{~cm}^{-1}\right)$ are attributed to weakly hydrogen bonded and free $\mathrm{O}-\mathrm{H}$ [27]. Additionally $\mathrm{CO}_{2}$, which have been known to adsorb on surface oxygen vacancies, were also detected on the surface (Supplementary Information Figure S2).

To better understand and quantify the formation of oxygen vacancies, air-annealed $\mathrm{ZnO}$ nanorods were exposed to UV irradiation in ultrahigh vacuum (UHV), followed by XPS measurements (Figure 5). Deconvolution of O1s peak shows 


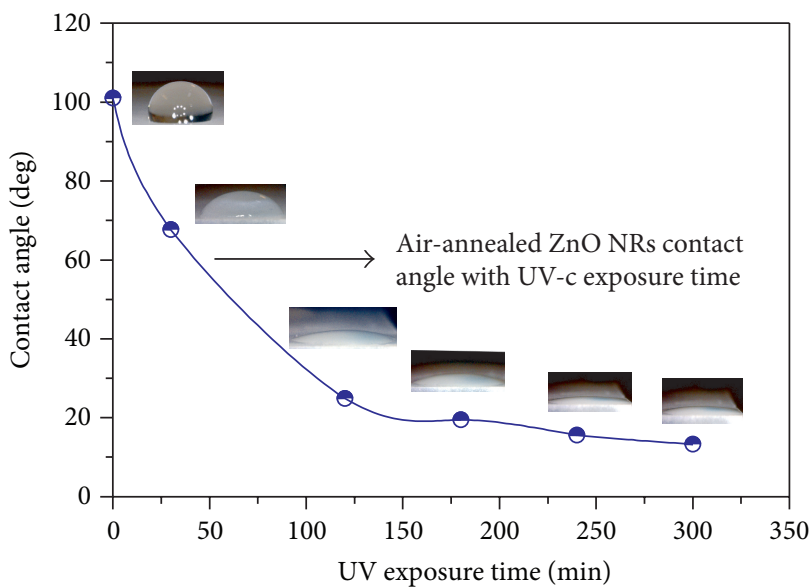

(a)

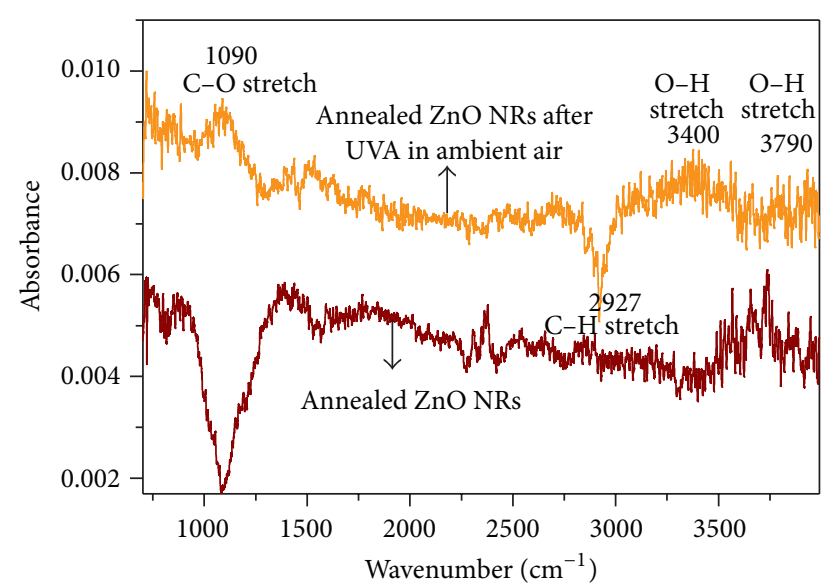

(b)

FIgURE 4: (a) Water contact angle measurements made on $350^{\circ} \mathrm{C}$ air-annealed $\mathrm{ZnO}$ NRs before and after UV-c exposure for varying times showing surface saturation after $\sim 180$ minutes. The insets show images of the water droplet $(5 \mu \mathrm{L})$ on the $\mathrm{ZnO} \mathrm{NR}$ surface for different UV exposure times and (b) infrared absorption spectra of air-annealed ZnO NRs before and after UV annealing in ambient air. The spectra show the increase in surface $\mathrm{OH}$ concentration, organic impurity degradation, and attachment of $\mathrm{CO}_{2}$ on the NR surfaces after UV annealing in air.

TABLE 1: Voltage and current magnitudes for a monolayer of CdTe QD's on ZnO NR's w/wo UVA in ambient air.

\begin{tabular}{lcc}
\hline Samples & $\begin{array}{c}\text { Short circuit current density } \\
\left(\mu \mathrm{A} / \mathrm{cm}^{2}\right)\end{array}$ & $\begin{array}{c}\text { Open circuit voltage } \\
(\mathrm{mV})\end{array}$ \\
\hline $\begin{array}{l}\text { Defect-free ZnO nanorods based CdTe QD-ZnO solar cell } \\
\text { photoelectrodes }\end{array}$ & $150(+/-8)$ & 37.5 \\
$\begin{array}{l}\text { UV defect induced ZnO nanorods based CdTe QD-ZnO solar cell } \\
\text { photoelectrodes }\end{array}$ & $250(+/-12)$ & 41.0 \\
\hline
\end{tabular}

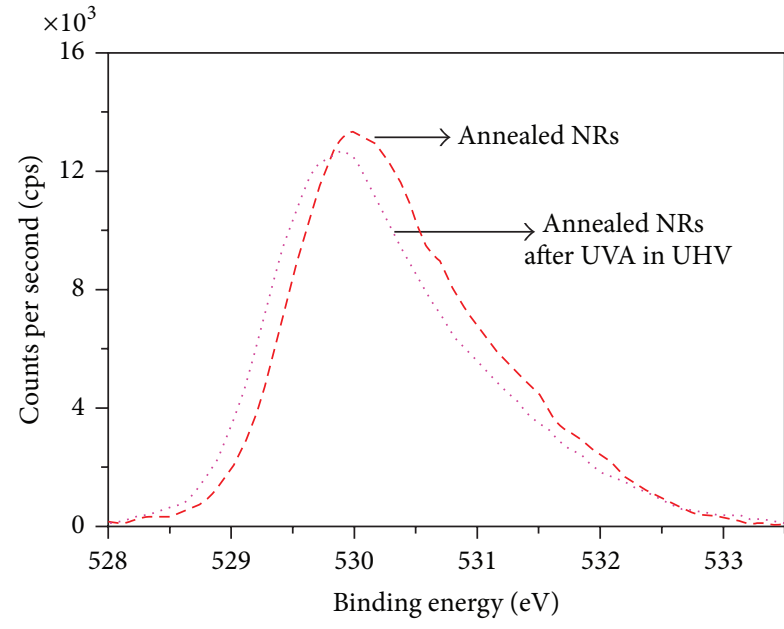

(a)

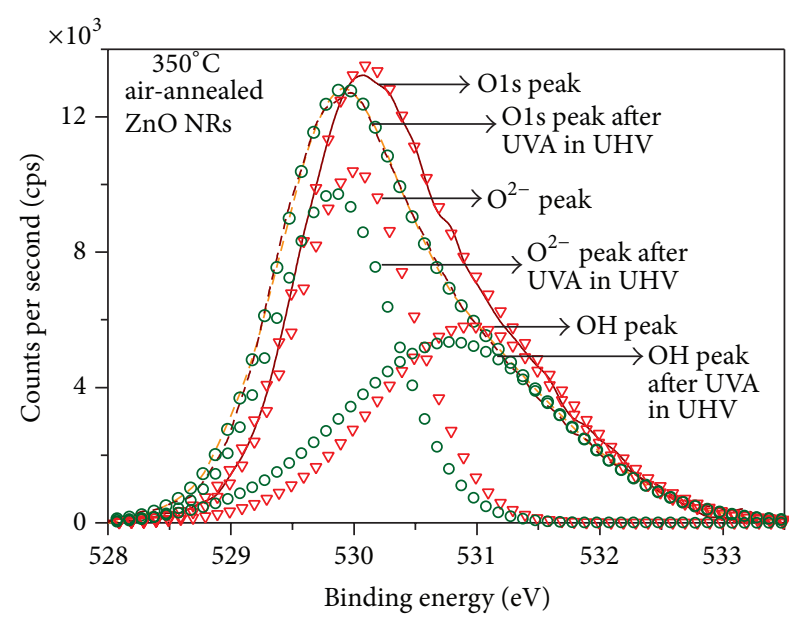

(b)

FIGURE 5: (a) X-ray photoelectron spectroscopy (XPS) of oxygen O1s spectra of $350^{\circ} \mathrm{C}$ air-annealed ZnO NRs before and after UV annealing in ultrahigh vacuum (UHV) environment. The peaks show an increase in oxygen content for as-prepared NRs while decreasing the oxygen in annealed NRs and (b) deconvolution of the O1s peaks showing a decrease in the lattice oxygen and surface hydroxyl content (red triangles) after UV annealing in UHV. 


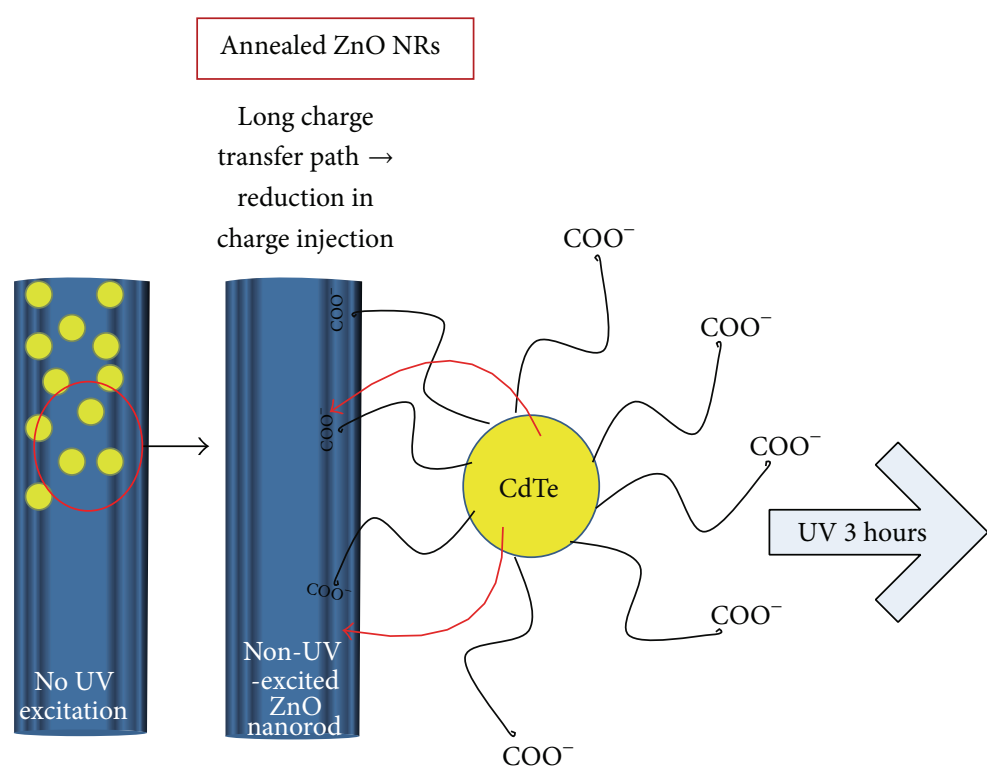

(a)

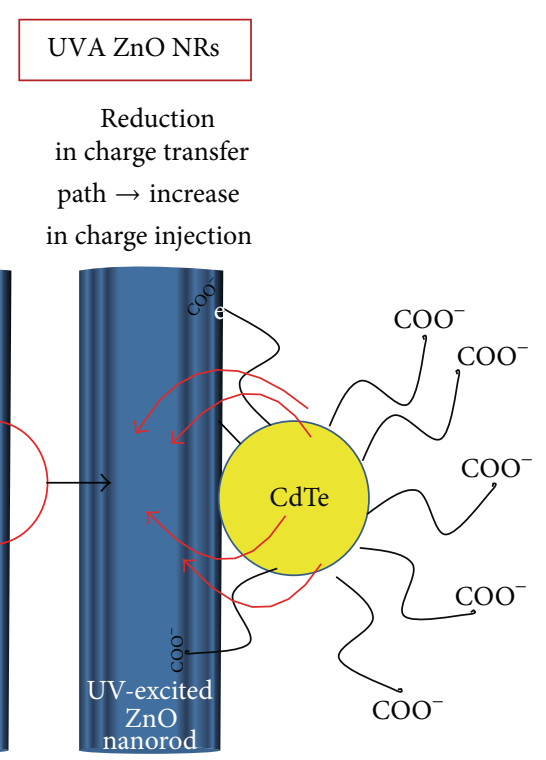

(b)

FIGURE 6: Schematic of change in attachment scheme and charge transfer efficiency of CdTe QDs on UV-annealed and air-annealed ZnO NR PE surfaces illustrating (a) CdTe attachment sites concentrated mainly on the upper surface of annealed ZnO NRs showing binding through the carboxylic end of 3-MPA; (b) change in charge transfer efficiency after UV annealing in ambient air as a result of uniform distribution of defect sites leading to an increase in the active surface area for the NRs, along with enhanced exposure of CdTe QD core to ZnO NR surface.

TABLE 2: XPS quantitative ratios of $\mathrm{O}^{2-}$ and $\mathrm{OH}$ peaks in airannealed and as-prepared $\mathrm{ZnO}$ NRs before and after UV annealing (UVA) in ultrahigh vacuum. "A" stands for air-annealed NRs and as-grown NRs before UV annealing in their respective rows.

\begin{tabular}{lccc}
\hline Samples & \multicolumn{2}{c}{ Ratio before and after UV annealing in UHV } \\
& $\mathrm{O} 1 \mathrm{~s}[\mathrm{UVA}] / \mathrm{O} 1 \mathrm{~s}[\mathrm{~A}]$ & $\mathrm{O}^{2-} \mathrm{UVA}^{2-}[\mathrm{A}]$ & $\mathrm{OH}[\mathrm{UVA}] / \mathrm{OH}[\mathrm{A}]$ \\
\hline $\begin{array}{l}\text { Annealed } \\
\text { ZnO }\end{array}$ & 0.98 & 0.95 & 1.02 \\
$\begin{array}{l}\text { As-grown } \\
\text { ZnO }\end{array}$ & 1.06 & 1.02 & 1.12 \\
\hline
\end{tabular}

that it could be fitted with 2 component peaks centred at $529.93 \mathrm{eV}$ and $530.88 \mathrm{eV}$ (Figure 5(b)), which are characteristic of $\mathrm{ZnO}$ lattice oxygen and surface adsorbed hydroxyls and moisture $[18,28]$. Integration of the area under the O1s spectra indicates the formation of surface oxygen vacancies upon UHV UV irradiation, manifesting in a reduction of surface oxygen content (Table 2 and Figure 5(a)). This confirms that UV annealing tends to release lattice and adsorbed oxygen, disturbing the equilibrium between creation and annihilation of photogenerated charges leading to the creation of localized defects on the stoichiometric $\mathrm{ZnO}$ surface [18].

The defects which are uniformly distributed on the $\mathrm{ZnO}$ nanorod surfaces act as QD bonding sites, improving the QD distribution as evident in the SEM images. Further, since the transfer of electrons from excited state of QDs to $\mathrm{ZnO}$ is a function of $\mathrm{ZnO}-\mathrm{QD}$ binding [29, 30], UV annealing induced change in $\mathrm{ZnO}$ surface energy may be the vital component which enhances the charge transfer efficiency across the $\mathrm{CdTe}-\mathrm{ZnO}$ junction. For semiconductors, the electron transfer rate from a single donating state (QD) to a continuum of accepting states like those in $\mathrm{ZnO}$ can been represented as [31]

$$
\begin{aligned}
& K_{\mathrm{ET}} \\
& =\frac{2 \pi}{\hbar} \int_{-\infty}^{\infty} \rho(E)|\widehat{H}(E)|^{2} \frac{1}{\sqrt{4 \pi \lambda K_{b} T}} \exp \left[\frac{(\lambda+\Delta G+E)^{2}}{4 \lambda K_{b} T}\right],
\end{aligned}
$$

where $K_{\mathrm{ET}}$ is the electron transfer rate, $\hbar$ is the reduced Planck constant, $K_{b}$ is Boltzmann's constant, $\lambda$ is system reorganization energy, $\Delta G$ is the change in system free energy, $\rho(E)$ is the density of accepting states which is also dependent on depth of defect states, and $\widehat{H}(E)$ is the overlap matrix element. Faster electron injection rates result when there is a better match between the system free energy $(\Delta G)$ and the system reorganization energy $(\lambda)$ [31]. In the region where $\Delta G \sim \lambda$ as in $\mathrm{ZnO}$, small changes in $\Delta G$ can cause steep changes in $K_{\mathrm{ET}}$, which might explain the faster injection dynamics after UV annealing. On a physical level, reactive surface species formed by the dissociative adsorption of water molecules on $\mathrm{ZnO}$ defect sites [32] can change the surface free energy, possibly leading to sporadic degradation of some 3-MPA ligands on the CdTe QDs. This will reduce the $\mathrm{ZnO}-\mathrm{CdTe}$ interfacial separation due to electrostatic attraction between the semiconductor surfaces [29], which in turn reduces the charge injection barrier, increasing the distance dependent electron tunnelling rate [30] as illustrated in Figures 6(a) and $6(\mathrm{~b})$. This phenomenon was clearly evident in the CdTe QD photoluminescence (PL) quenching measurements 


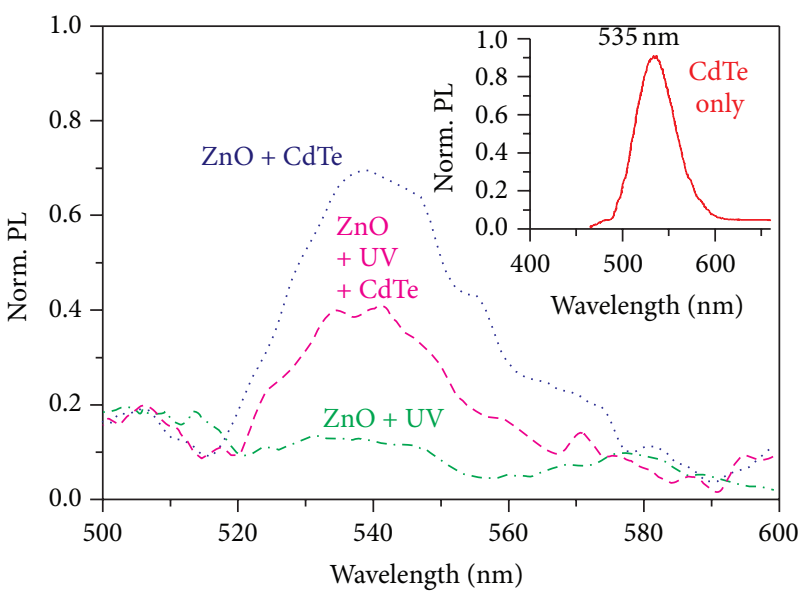

FIgURE 7: Normalized photoluminescence (PL) measurements on CdTe QD decorated ZnO NR substrates showing lower luminescence (improved charge transfer from QD to $\mathrm{ZnO}$ ) in $\mathrm{UV}$ treated $\mathrm{ZnO}$ substrates as compared to air-annealed $\mathrm{ZnO}$ substrates. The excitation was carried out at $450 \mathrm{~nm}$, where $\mathrm{ZnO}$ is inactive to avoid interference by $\mathrm{ZnO}$ emission peaks.

conducted on UV-exposed and air-annealed ZnO PEs. UVexposed PEs showed better PL quenching, suggesting a lower resistance to the charge injection phenomenon and a more intimate interface between the $\mathrm{ZnO}$ nanorods and CdTe QDs (Figure 7). It is to be noted that the excitation wavelength used for the PL characterization was $450 \mathrm{~nm}$, where $\mathrm{ZnO}$ is inactive, while CdTe QD is highly active. This negates the interference of $\mathrm{ZnO}$ emission with $\mathrm{CdTe} \mathrm{QD}$ emission, enabling measurement of only CdTe emission for better characterization.

We thus propose a scheme where photoinduced surface defects on $\mathrm{ZnO}$ nanorods can transform a moderately active planar $\mathrm{ZnO}$ surface into a high energy reactive surface, which enhances the QD loading while simultaneously decreasing the interfacial charge transfer resistance due to direct electrostatic attachment of the QDs on the $\mathrm{ZnO}$ supports. Utilization of such a facile surface modification technique is independent of the type of QD used and can be useful in various surface related phenomena making it an effective tool for enhancing surface chemistry of semiconductor nanostructures.

\section{Conclusion}

We have introduced a controlled photomediated approach to create uniformly distributed surface charges on $\mathrm{ZnO}$, leading to increase in $\mathrm{ZnO}$ surface energy. The increased surface energy showed greater hydrophilicity with water contact angle (WCA) changing from $100^{\circ}$ before UV exposure to $12^{\circ}$ after UV exposure and was characterized by XPS and was partly found to be oxygen vacancies. The hydrophilic surfaces were shown to have better affinity towards QD loading while simultaneously increasing the efficiency of charge transfer across the ZnO-QD interface. Model solar cells made from the hydrophilic surfaces show $10 \%$ and $66 \%$ increase in voltage and current, respectively, opening a new approach for incorporating narrow band absorption control of sensitized cells along with the advantage of enhanced sensitization and better interfacial characteristics. Such surfaces can improve charge separation at the interface and can be utilized in diverse applications involving surface dominated reactions.

\section{Conflict of Interests}

The authors declare that there is no conflict of interests regarding the publication of this paper.

\section{Acknowledgments}

The authors would like to thank the Centre of Excellence in Nanotechnology at the Asian Institute of Technology and the Chair in Nanotechnology Programme of the Research Council of Oman for financial support.

\section{References}

[1] S. Danwittayakul, K. Lakshman, S. Al-Harthi, and J. Dutta, "Enhanced hydrogen selectivity via photo-engineered surface defects for methanol steam reformation using zinc oxidecopper nanocomposite catalysts," Applied Catalysis A: General, vol. 471, pp. 63-69, 2014.

[2] J. Tang, K. W. Kemp, S. Hoogland et al., "Colloidal-quantum-dot photovoltaics using atomic-ligand passivation," Nature Materials, vol. 10, pp. 765-771, 2011.

[3] H. J. Yun, T. Paik, M. E. Edley, J. B. Baxter, and C. B. Murray, "Enhanced charge transfer kinetics of CdSe quantum dotsensitized solar cell by inorganic ligand exchange treatments," ACS Applied Materials and Interfaces, vol. 6, no. 5, pp. 37213728, 2014.

[4] E. Martínez-Ferrero, I. M. Seró, J. Albero, S. Giménez, J. Bisquert, and E. Palomares, "Charge transfer kinetics in CdSe quantum dot sensitized solar cells," Physical Chemistry Chemical Physics, vol. 12, no. 12, pp. 2819-2821, 2010.

[5] A. Ruland, C. Schulz-Drost, V. Sgobba, and D. M. Guldi, "Enhancing photocurrent efficiencies by resonance energy transfer in CdTe quantum dot multilayers: towards rainbow solar cells," Advanced Materials, vol. 23, no. 39, pp. 4573-4577, 2011.

[6] J. Maçaira, L. Andrade, and A. Mendes, "Review on nanostructured photoelectrodes for next generation dye-sensitized solar cells," Renewable and Sustainable Energy Reviews, vol. 27, pp. 334-349, 2013.

[7] J. Zhang, W. Peng, Z. Chen, H. Chen, and L. Han, "Energy band tunable $\mathrm{Ti}_{x} \mathrm{Sn}_{1-x} \mathrm{O}_{2}$ photoanode for efficient non- $\mathrm{TiO}_{2}$ type dye sensitized solar cells," Journal of Materials Chemistry A, vol. 1, no. 29, pp. 8453-8463, 2013.

[8] T. W. Hamann, R. A. Jensen, A. B. F. Martinson, H. van Ryswyk, and J. T. Hupp, "Advancing beyond current generation dyesensitized solar cells," Energy and Environmental Science, vol. 1, no. 1, pp. 66-78, 2008.

[9] P. Uthirakumar, H. G. Kim, and C.-H. Hong, "Zinc oxide nanostructures derived from a simple solution method for solar cells and LEDs," Chemical Engineering Journal, vol. 155, no. 3, pp. 910-915, 2009.

[10] M. Grätzel, "Dye-sensitized solar cells," Journal of Photochemistry and Photobiology C: Photochemistry Reviews, vol. 4, no. 2, pp. 145-153, 2003. 
[11] M. Law, L. E. Greene, J. C. Johnson, R. Saykally, and P. Yang, "Nanowire dye-sensitized solar cells," Nature Materials, vol. 4, no. 6, pp. 455-459, 2005.

[12] H. Majidi and J. B. Baxter, "Electrodeposition of CdSe coatings on $\mathrm{ZnO}$ nanowire arrays for extremely thin absorber solar cells," Electrochimica Acta, vol. 56, no. 6, pp. 2703-2711, 2011.

[13] A. Sugunan, H. C. Warad, M. Boman, and J. Dutta, "Zinc oxide nanowires in chemical bath on seeded substrates: role of hexamine," Journal of Sol-Gel Science and Technology, vol. 39, no. 1, pp. 49-56, 2006.

[14] G.-Y. Lan, Z. Yang, Y.-W. Lin, Z.-H. G. Lin, H.-Y. Liao, and H.T. Chang, "A simple strategy for improving the energy conversion of multilayered CdTe quantum dot-sensitized solar cells," Journal of Materials Chemistry, vol. 19, no. 16, pp. 2349-2355, 2009.

[15] J. Briscoe, D. E. Gallardo, S. Hatch, V. Lesnyak, N. Gaponik, and S. Dunn, "Enhanced quantum dot deposition on $\mathrm{ZnO}$ nanorods for photovoltaics through layer-by-layer processing," Journal of Materials Chemistry, vol. 21, no. 8, pp. 2517-2523, 2011.

[16] T. Bora, H. H. Kyaw, and J. Dutta, "Zinc oxide-zinc stannate core-shell nanorod arrays for CdS quantum dot sensitized solar cells," Electrochimica Acta, vol. 68, pp. 141-145, 2012.

[17] A. Sivapunniyam, N. Wiromrat, M. T. Z. Myint, and J. Dutta, "High-performance liquefied petroleum gas sensing based on nanostructures of zinc oxide and zinc stannate," Sensors and Actuators, B: Chemical, vol. 157, no. 1, pp. 232-239, 2011.

[18] R.-D. Sun, A. Nakajima, A. Fujishima, T. Watanabe, and K. Hashimoto, "Photoinduced surface wettability conversion of $\mathrm{ZnO}$ and $\mathrm{TiO}_{2}$ Thin Films," The Journal of Physical Chemistry B, vol. 105, no. 10, pp. 1984-1990, 2001.

[19] M. T. Z. Myint, N. S. Kumar, G. L. Hornyak, and J. Dutta, "Hydrophobic/hydrophilic switching on zinc oxide micro-textured surface," Applied Surface Science, vol. 264, pp. 344-348, 2013.

[20] C. Soci, A. Zhang, B. Xiang et al., "ZnO nanowire UV photodetectors with high internal gain," Nano Letters, vol. 7, no. 4, pp. 1003-1009, 2007.

[21] S. Baruah and J. Dutta, "Hydrothermal growth of $\mathrm{ZnO}$ nanostructures," Science and Technology of Advanced Materials, vol. 10, no. 1, Article ID 013001, 2009.

[22] S. Baruah and J. Dutta, "pH-dependent growth of zinc oxide nanorods," Journal of Crystal Growth, vol. 311, no. 8, pp. 25492554, 2009.

[23] J. Duan, L. Song, and J. Zhan, “One-pot synthesis of highly luminescent CdTe quantum dots by microwave irradiation reduction and their $\mathrm{Hg}^{2+}$-sensitive properties," Nano Research, vol. 2, no. 1, pp. 61-68, 2009.

[24] Y.-L. Lee and C.-H. Chang, "Efficient polysulfide electrolyte for CdS quantum dot-sensitized solar cells," Journal of Power Sources, vol. 185, no. 1, pp. 584-588, 2008.

[25] A. F. Stalder, G. Kulik, D. Sage, L. Barbieri, and P. Hoffmann, "A snake-based approach to accurate determination of both contact points and contact angles," Colloids and Surfaces A: Physicochemical and Engineering Aspects, vol. 286, no. 1-3, pp. 92-103, 2006.

[26] H. Noei, H. Qiu, Y. Wang, E. Löffler, C. Wöll, and M. Muhler, "The identification of hydroxyl groups on $\mathrm{ZnO}$ nanoparticles by infrared spectroscopy," Physical Chemistry Chemical Physics, vol. 10, no. 47, pp. 7092-7097, 2008.

[27] T. Noguchi, "FTIR detection of water reactions in the oxygenevolving centre of photosystem II," Philosophical Transactions of the Royal Society B: Biological Sciences, vol. 363, no. 1494, pp. 1189-1194, 2008.
[28] P. S. Xu, Y. M. Sun, C. S. Shi, F. Q. Xu, and H. B. Pan, “The electronic structure and spectral properties of $\mathrm{ZnO}$ and its defects," Nuclear Instruments and Methods in Physics Research Section B: Beam Interactions with Materials and Atoms, vol. 199, pp. 286290, 2003.

[29] D. R. Pernik, K. Tvrdy, J. G. Radich, and P. V. Kamat, “Tracking the adsorption and electron injection rates of CdSe quantum dots on $\mathrm{TiO}_{2}$ : Linked versus direct attachment," The Journal of Physical Chemistry C, vol. 115, no. 27, pp. 13511-13519, 2011.

[30] R. S. Dibbell and D. F. Watson, "Distance-dependent electron transfer in tethered assemblies of cds quantum dots and $\mathrm{TiO}_{2}$ nanoparticles," Journal of Physical Chemistry C, vol. 113, no. 8, pp. 3139-3149, 2009.

[31] K. Tvrdy, P. A. Frantsuzov, and P. V. Kamat, "Photoinduced electron transfer from semiconductor quantum dots to metal oxide nanoparticles," Proceedings of the National Academy of Sciences of the United States of America, vol. 108, no. 1, pp. 29-34, 2011.

[32] J. Doménech and A. Prieto, "Stability of $\mathrm{ZnO}$ particles in aqueous suspensions under UV illumination," Journal of Physical Chemistry, vol. 90, no. 6, pp. 1123-1126, 1986. 

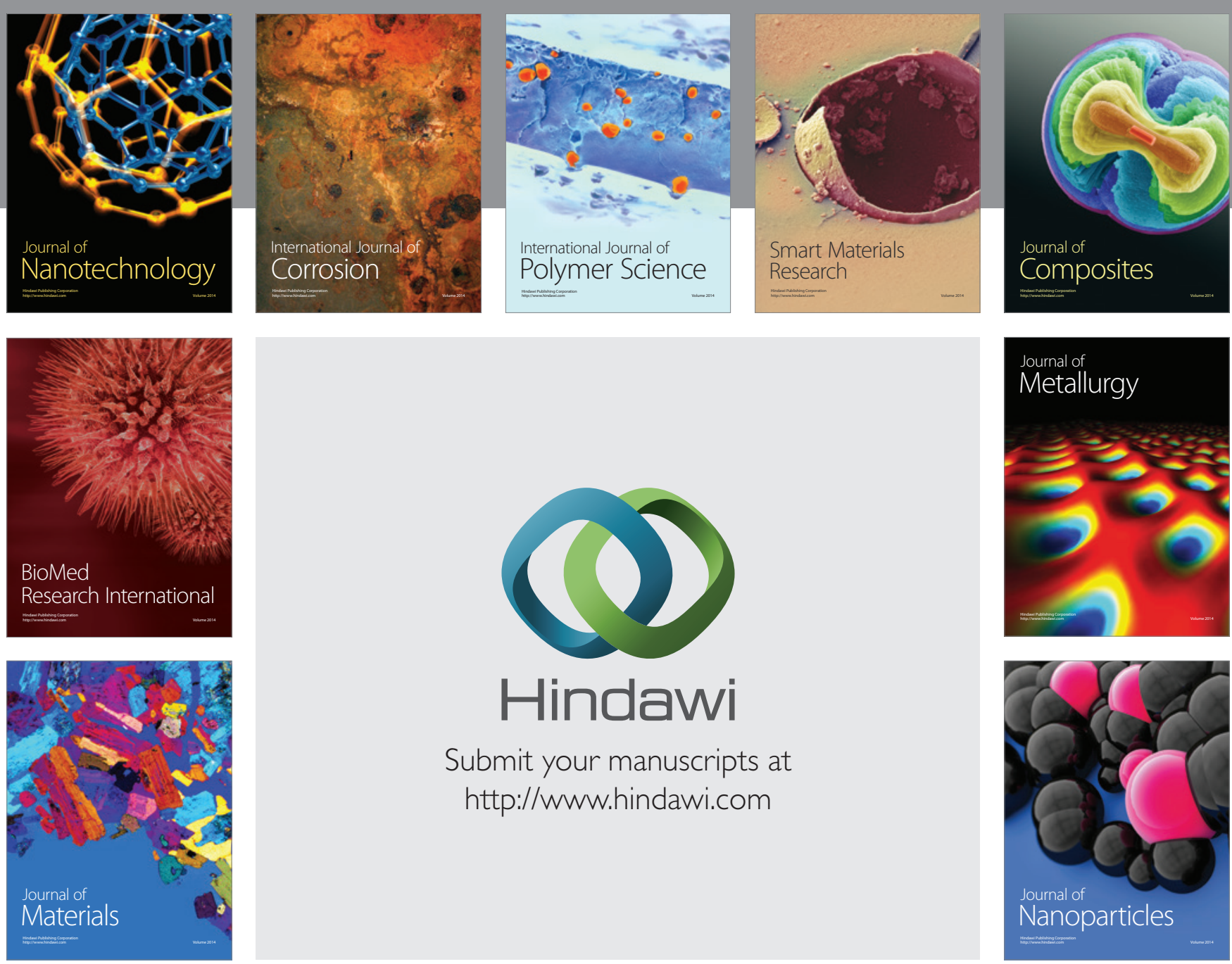

Submit your manuscripts at http://www.hindawi.com
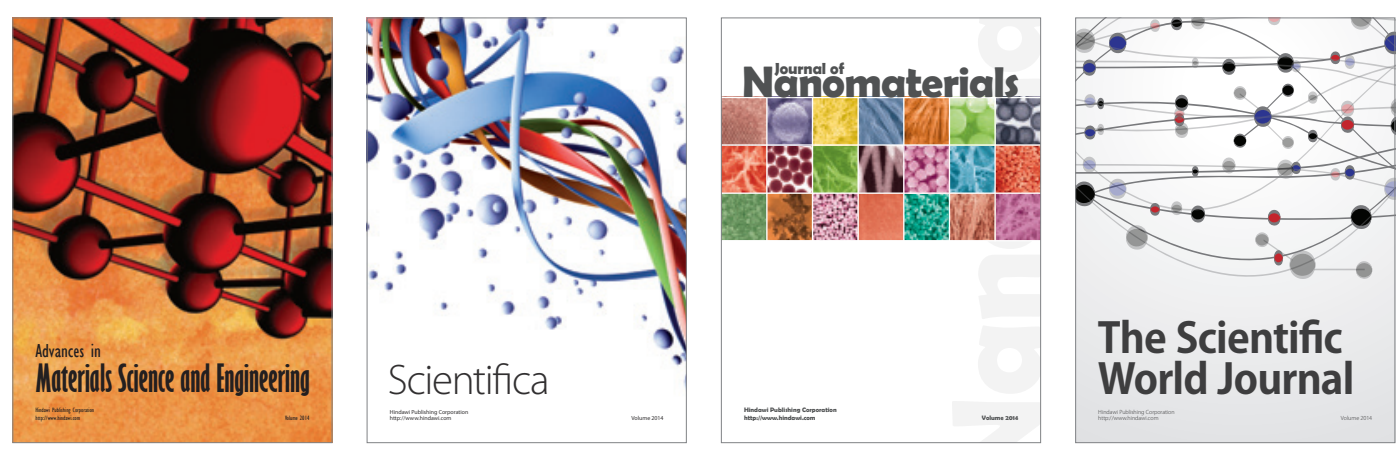

\section{The Scientific World Journal}
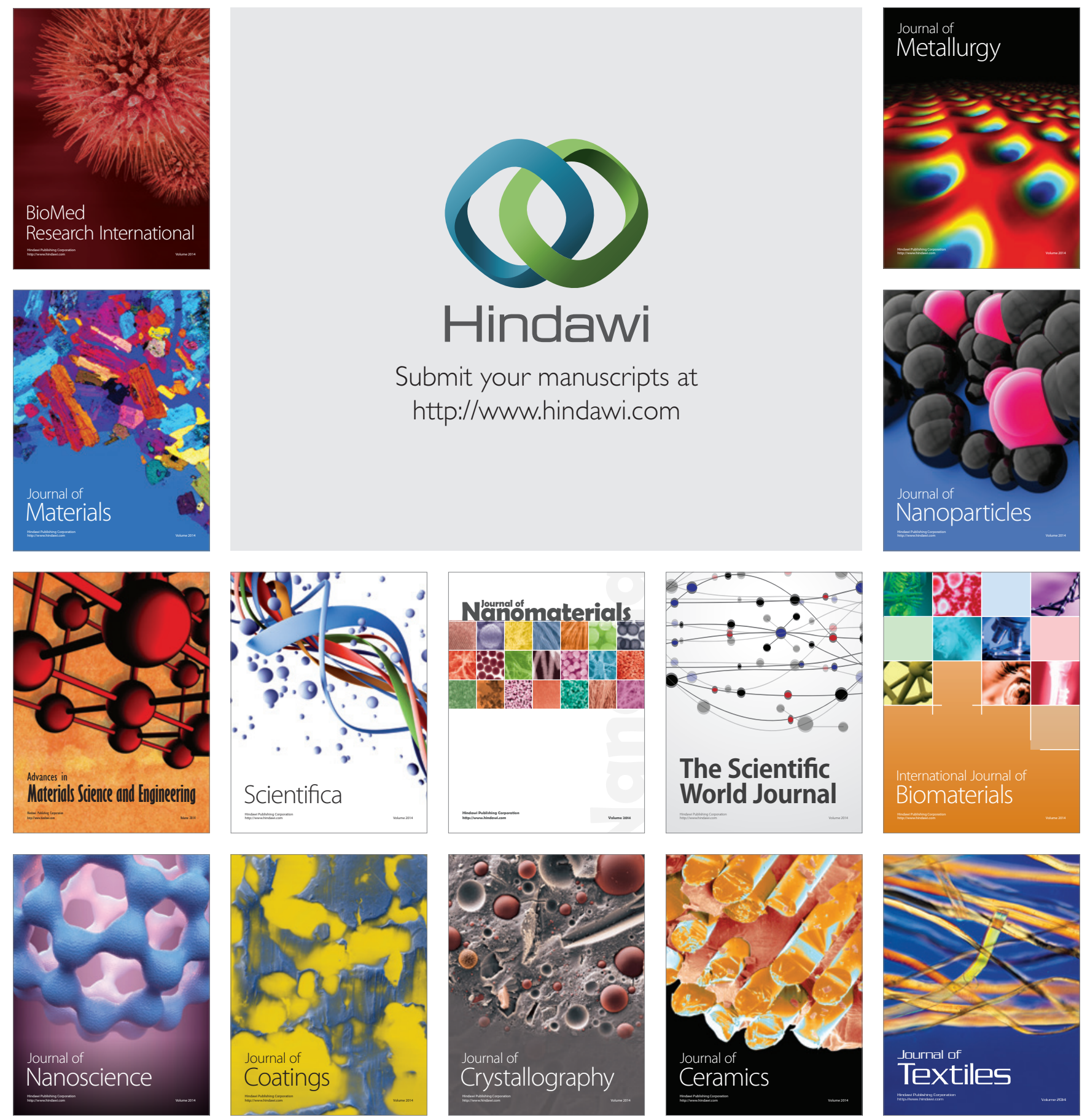